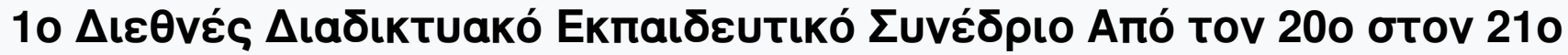

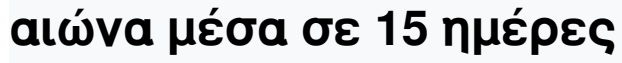

Ap. $1(2021)$

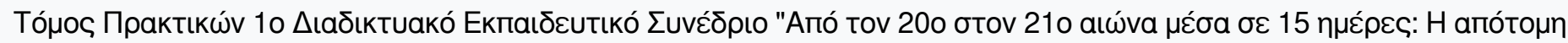

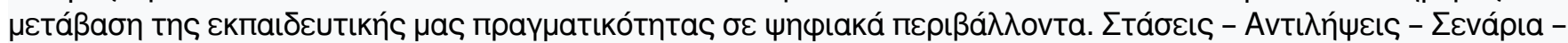

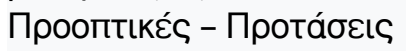

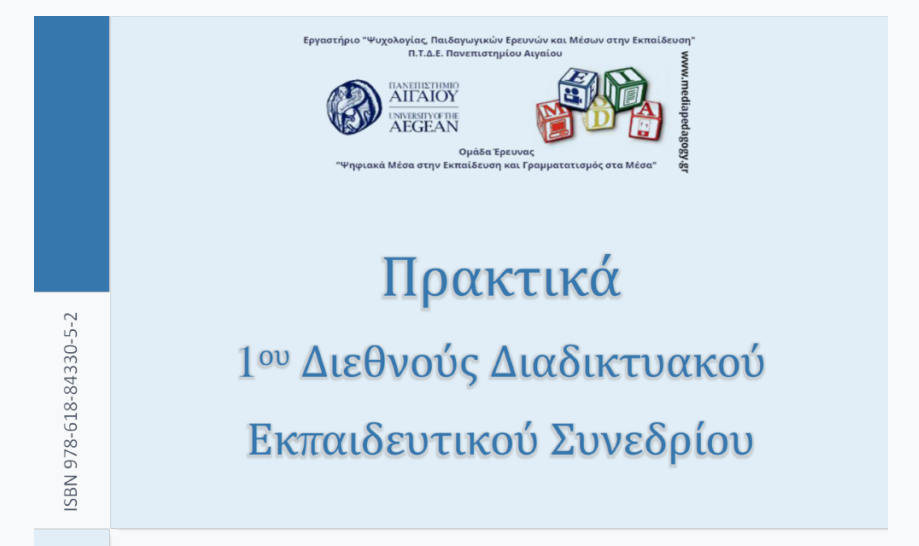

The response of schools in Scotland to coronavirus: 'Glow'ing together

Katrina Foy, David Johnston, Aloyise Mulligan, Rachel Shanks

doi: $10.12681 /$ online-edu.3216

H $\alpha \pi$ tó

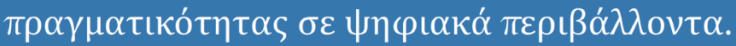

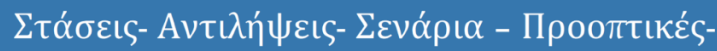

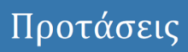

$3,4 \& 5$ Iovגíou 2020

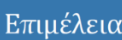

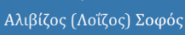

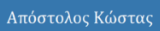

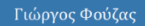

Baoìnıs Парй́oxou 


\title{
The response of schools in Scotland to coronavirus: 'Glow'ing together
}

\author{
Katrina Foy ${ }^{1}$, David H, Johnston ${ }^{2}$, Aloyise Mulligan ${ }^{3}$, Rachel Shanks ${ }^{4}$ \\ kfoy@abdn.ac.uk, d.h.johnston@abdn.ac.uk, aloyisemulligan@abdn.ac.uk, \\ r.k.shanks@abdn.ac.uk \\ ${ }^{1}$ Mrs/Lecturer, \\ 2 Dr/Lecturer, \\ ${ }^{3} \mathrm{Ms} /$ Lecturer \\ ${ }^{4} \mathrm{Dr} /$ Senior Lecturer
}

\begin{abstract}
Four researchers at the University of Aberdeen investigated the impact of the novel coronavirus (COVID19) lockdown on teachers' practice in Scotland. We analysed information collected from primary teachers, a deputy primary school head teacher, secondary teachers of Biology, English, Mathematics, a secondary school head teacher and two regional education officers on how teachers reacted, adapted and responded to the first nationwide lockdown in response to COVID-19 ( $n=10)$. Home (first space) and school (second space) are often viewed as separate contexts with clearly defined and impermeable boundaries, although children participate in both spaces (Pahl \& Kelly, 2005). We sought to understand the 'third space' (Bhabha, 1990) between school and home that was created through online and blended teaching and learning. Working in such a space has implications and consequences for the teachers who have to institute new routines using new technologies and think about teaching differently.
\end{abstract}

Keywords: Third space, remote teaching, COVID-19

\section{Introduction}

With the closure of school and nursery buildings in Scotland from Tuesday $24^{\text {th }}$ March 2020 a team of four researchers in the School of Education at the University of Aberdeen were interested in finding out about educators' responses to teaching remotely. Early year practitioners, primary and secondary school teachers were contacted in six of the thirty-two local authorities in Scotland and asked about their approach to remote teaching (Aberdeen City, Aberdeenshire, Glasgow City, Highland, Perth and Kinross, and Moray).

\section{Teaching remotely}

Primary and secondary teachers identified Glow as the preferred route to communicate with pupils. Teachers in primary and secondary schools said Glow virtual learning environment was the way they accessed platforms (Teams and Google Classroom) while Early Years teachers saw Glow as having least relevance as not all children have a log in.

As well as delivering online learning through Glow, local authorities had issued their own guidance and recommendations. Many local authorities, such as Aberdeen City and Aberdeenshire, formed digital hubs where pupils and teachers received additional support to deliver learning and teaching. The participants in this study said that the main platforms deployed to deliver teaching were Google classrooms, Microsoft Teams and Seesaw.

According to the participants the choice of whether to use Google Classroom or Microsoft Teams to connect with pupils was left up to each individual school. They said that both

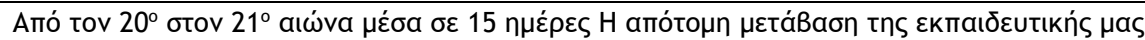

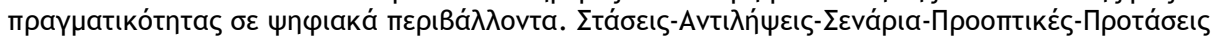


Google Classroom and Microsoft Teams were a great way to keep in touch with pupils, deliver new learning, ask questions and support pupils.

They stated that there was clear guidance from local authorities about data protection issues when using apps such as Facetime, Messenger, WhatsApp as these consumer services place data and that of pupils into consumer platforms over which there is no governance.

There were a variety of collaborative learning tools promoted by local authorities such as G Suite Docs or Office 365. Collaboration features are available in these particular tools.

'The wide range of communication and collaboration tools available through the Glow service have helped us to ensure that learning continues outside of the classroom for our pupils' - Dundee Local Authority.

Each local authority issued its own guidance which produced inconsistencies, for example Stirling had no live/synchronous activities. Participants told us that they worked to engage vulnerable pupils and make sure they had access and connectivity. Most teachers noted a lack of engagement from pupils. Secondary teachers were most concerned about the impact that lack of engagement would have on learning for examinations. Lack of engagement by secondary pupils was most noticeable in relation to 'live' lessons.

\section{Engagement with parents}

Early Years teachers saw the most interaction with parents - they uploaded 'evidence' of children engaging in offline activities such as photos and videos. There was also involvement of family members in the learning activities, in particular in practical activities away from the screen, using resources in the home. Most children in the Early Years were participating through parents, rather than with peers.

Participants from all sectors stated that some families requested paper copies of work to be brought to them. While there was most parental engagement in the Early Years, there was little contact between parents/carers and secondary school teachers.

\section{Types of work set remotely}

Primary teachers stated that they set daily tasks, while for secondary teachers it was mainly weekly tasks that were set. Primary teachers said they held some synchronous sessions and the pupils often just wanted a chance to talk to their peers rather than engage in teacherorganised learning. They also recorded some lessons. In both primary and secondary settings pupils were asked to complete independent tasks which were uploaded for feedback from the teacher. All participants reported some children not engaging, in particular, children who were already vulnerable. Only one participant noted full participation from the pupils they teach. For the others it was usual that live/synchronous lessons were not fully attended. Secondary school teachers said that they were trying to keep progression in course work with differences between the amount of work set depending on the subject.

The researchers noted that the way online learning was implemented in each sector mirrored the way the curriculum is mainly interpreted in that sector, for example teachers in secondary schools followed a more traditional mode of teaching and learning by setting tasks/worksheets to be completed on a weekly basis.

\section{ICT skills}

In all sectors, Early Years, primary and secondary, all the participants felt that they had been upskilled in their use of ICT during the lockdown.

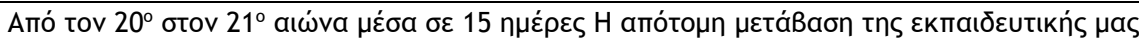

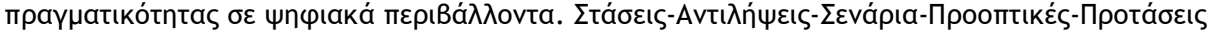




\section{Conclusion/Discussion}

There are implications, too, for the relationships which teachers might be able to have with their pupils. We found that teachers accessed platforms such as Microsoft Teams and Google Classroom via the Glow virtual learning environment. The Early Years teachers saw Glow as having least relevance as not all children had a log-in and these teachers had most interactions with parents. All teachers felt that they had been upskilled in their use of ICT since lockdown. It is worth noting that only one teacher noted full participation from the pupils they teach. So far, we have not been able to identify a specific third space being created (Bhabha, 1990; Guttierrez, Baquedano-Lopez \& Tejeda, 2000; Pahl \& Kelly, 2005) but our intention is to return to the participants to investigate this further.

\section{References}

Bhabha, H., (1990). Nation and narration. London: Routledge.

Guttierrez, K., Baquedano-Lopez, P., \& Tejeda, C., (2000). Rethinking diversity: hybridity and hybrid language practices in the third space. Mind, Culture and Activity: an International Journal, 6(4), 286-303. Moll et al, 1992)

Pahl, K., \& Kelly, S., (2005). Family literacy as a third space between home and school: some case studies of practice. Literacy, 39(2), 91-96

Aпó tov $20^{\circ}$ otov $21^{\circ}$ aı

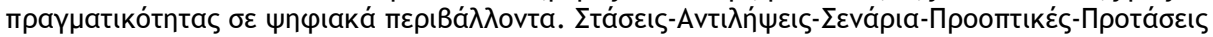

